\title{
Is Clipping Superior to Cauterization in the Treatment of Palmar Hyperhidrosis?
}

\author{
Alper Findikcioglu ${ }^{1}$ Dalokay Kilic ${ }^{2}$ Ahmet Hatipoglu ${ }^{2}$ \\ ${ }^{1}$ Department of Thoracic Surgery, Baskent University Adana Medical \\ Center, Adana, Turkey \\ 2 Department of Thoracic Surgery, Baskent University Faculty of \\ Medicine, Ankara, Turkey \\ Address for correspondence Alper Findikcioglu, MD, Department of \\ Thoracic Surgery, Baskent University Adana Medical Center, Baskent \\ hastanesi Dadaloğlu M 39 sk, No 6 Yüregir, Adana 01250, Turkey \\ (e-mail: alperfindikci@hotmail.com).
}

Thorac Cardiovasc Surg 2014;62:445-449.

\begin{abstract}
Background Endoscopic thoracic sympathectomy has been accepted as the most effective treatment for palmar hyperhidrosis ( $\mathrm{PH})$. However, there is a debate regarding the surgical techniques in terms of effectiveness, recurrence, and reversibility. In this study, sympathetic chain disruptions were compared in terms of whether the clipping or ablation technique had an effect on the long-term outcomes of patients who underwent thoracic sympathectomy for primary $\mathrm{PH}$.

Patients and Methods All patients who underwent video-thoracoscopic sympathectomy for PH between May 2008 and October 2011 were included. Single-port bilateral sympathectomy was performed depending on the sweat distribution. As a standard approach, rib-based terminology was used to describe the blockade level of the sympathetic ganglia, and single-level R3 sympathectomy (between R3 and R4) was performed in all patients. The type of sympathectomy was changed. Monopolar electrocautery was first performed and 5-mm clips were then used for nerve disruption. Both techniques were evaluated and compared in terms of effectiveness, reversibility, and recurrence.

Results Cauterization of the sympathetic chain was applied in 28 (47\%) (Group A) patients and clipping in $32(53 \%)$ patients (Group B). CH was the most common adverse effect and was observed in 43 (71.6\%) patients (Group A, 71.4\%; Group B, 71.8\%; $p=0.8)$. The success rate was $93 \%$ for Group $A$ and $100 \%$ for Group $B(p=0.15)$. The satisfaction rate for Group A was $83 \%$ and for Group B was $86 \%(p=0.77)$. In Group A two patients (7\%), and in Group B three patients (9\%) requested reversibility because of severe compensatory hyperhidrosis. Overly dry hands were the other most common side effect and were identified in $12(25 \%)$ patients. Recurrences were observed in 11 patients in Group A and 4 patients in Group B ( 19 vs. $6 \% ; p=0.01$ ). The mean follow-up time was $33 \pm 10.5$ months (range, 13-53 months).

Conclusion Both clipping and cauterization are highly effective for the treatment of $\mathrm{PH}$. The methods are comparable in terms of effectiveness and side effects despite the

\section{Keywords}

- thoracoscopy/VATS

- quality of life

- hyperhidrosis fact that the recurrence rate was higher in the cauterization group. Potential reversibility of compensatory sweating was not observed in our series. Identification of ideal candidates for surgery and education of patients about the permanent side effects of sympathectomy might make these techniques more convenient.
\end{abstract}

received

March 16, 2013

accepted after revision

May 24, 2013

published online

July 9,2013 (c) 2014 Georg Thieme Verlag KG

Stuttgart · New York
DOI http://dx.doi.org/ 10.1055/s-0033-1348920. ISSN 0171-6425. 


\section{Introduction}

Primary palmar hyperhidrosis (PH) is an idiopathic condition that may cause social, emotional, and professional inconvenience. Eccrine sweat glands are responsible for the development of $\mathrm{PH}$ and are innervated by the sympathetic nervous system. Increased sympathetic activity that occurs spontaneously or because of an abnormal central response to increased temperature or emotional changes may result in excessive sweating. ${ }^{1}$ Conservative treatment of $\mathrm{PH}$, such as medication (anticholinergic drugs), Botox, or iontophoresis, usually provides temporary benefits, and these nonsurgical treatments are not without associated side effects. ${ }^{2,3}$

Surgical treatment of $\mathrm{PH}$ (video-thoracoscopic sympathectomy) has proven itself in terms of efficiency and reliability. 4,5 However, patient dissatisfaction with sympathectomy has led to reconsideration of the surgical approach. It is well established that compensatory hyperhidrosis $(\mathrm{CH})$ influences patients' satisfaction and quality of life. The surgery was evolved to increase patient satisfaction and presently has a high success rate and fewer side effects. ${ }^{6}$ Limited sympathetic chain disruption under the R2 ganglion level has been recommended for patients with palmar and palmoaxillary sweating to reduce $\mathrm{CH}^{7}$ There is a debate regarding the best surgical technique for sympathectomy in terms of whether interruption with electrocautery or blockade with clips should be performed, despite the fact that both the methods have good results if the level of division is correct. Although controversial, the potential reversibility of clipping makes this method more favorable than cauterization. In this study, sympathetic chain interruption techniques were compared in terms of efficiency, recurrence, and reversibility.

\section{Patients and Methods}

Between May 2008 and September 2011, all patients who underwent thoracic sympathectomy for PH were enrolled in this study. Patients with facial flashing and isolated axillary hyperhidrosis were excluded. All surgical procedures were performed with the patients in the semi-sitting position with arms abducted under general anesthesia with double-lumen endotracheal intubation. Single-stage, bilateral, uniport video-thoracoscopy was performed with the placement of a thoracoscopic port (11-mm trocar) on the anterior axillary line of the third intercostal space. A 5-mm, 30-degree thoracoscope was used for visualization. The type of sympathetic chain interruption has changed because of the popularity of the clipping technique. Monopolar electrocautery was used successfully for ablation of the sympathetic ganglia in the first 30 patients (47\%), and blockade of the sympathetic chain with titanium clips was performed in the remaining 36 patients (53\%). For sympathectomy, with reference to the rib level, the overlying parietal pleura was incised between the R3 and R4 levels over the sympathetic chain. The sympathetic chain was clipped or cauterized on the top of the third rib and on the bottom of the fourth rib ( - Fig. 1). A small-bore catheter was inserted for reexpansion of the lungs, and the patients were then extubated in the operating room. In three patients, chest

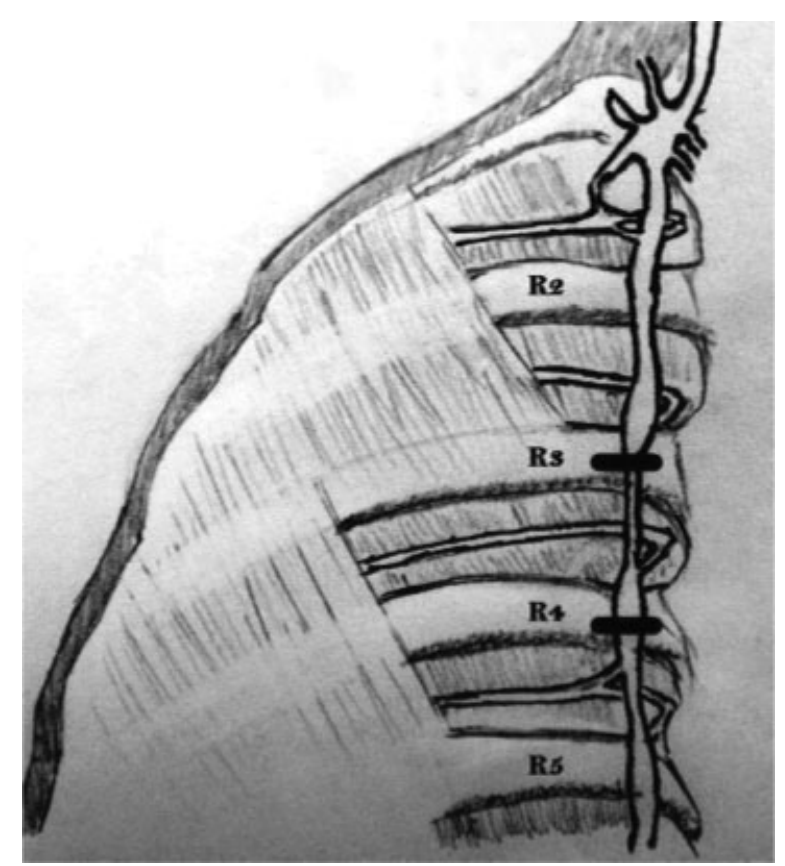

Fig. 1 R3 sympathectomy.

tubes were inserted for serious apical pleural adhesions. All patients, excluding one with air leakage, were discharged within 24 hours. All surgical procedures were performed by the same surgical team.

\section{Data Collection}

Clinical charts were reviewed for patient demographic data, family history, and prior treatment modalities. The patients were contacted by telephone and, if possible, outpatient visits to assess operative outcomes such as degree of compensatory sweating, persistent complications, and recurrence. Patient satisfaction was evaluated using a questionnaire form (-Table 1). The results were analyzed using a 5-point satisfaction scale (-Table 2). SPSS version 17 was used for statistical evaluation (Statistical Package for Social Science, SPSS Inc., Chicago, Illinois, United States). Continuous variables were expressed as the mean \pm standard deviation and compared by student $t$-test. Categorical variables were expressed by number and frequencies (percent). The chi-square test was used to compare proportions. All results were considered to be significant at $p$ values of less than 0.05 .

\section{Results}

Of the 66 patients who underwent R3 sympathectomy operations, 60 were enrolled in this study. The patients comprised 36 (60\%) females and 24 (40\%) males with a mean age of $24.10 \pm 6.21$ years (range, $15-43$ years). $\mathrm{PH}$ accompanied by axillary hyperhidrosis was present in 38 (63\%) patients, and plantar hyperhidrosis was present in 58 (97\%) patients. A familial history was present in $25 \%$ of the patients. Approximately, $83 \%$ of patients were referred to endocrinology and metabolism clinics and $97 \%$ were admitted to a dermatologist before the thoracic surgery. Alternative medical treatments, 
Table 1 The 5-point satisfaction scale and the patients' distributions

\begin{tabular}{|l|l|l|l|l|}
\hline Level of satisfaction & Point & $\begin{array}{l}\text { All patients } \\
\mathbf{N}=\mathbf{6 0}(\%)\end{array}$ & $\begin{array}{l}\text { Group A } \\
\mathbf{n = 2 8}\end{array}$ & $\begin{array}{l}\text { Group B } \\
\boldsymbol{n}=\mathbf{3 2}\end{array}$ \\
\hline Very satisfied & $10-9$ & $39(65)$ & 17 & 22 \\
\hline Satisfied & $8-7$ & $12(20)$ & 8 & 4 \\
\hline Neither satisfied nor dissatisfied & $6-5$ & - & - & - \\
\hline Dissatisfied & $4-3$ & $4(7)$ & 3 & 1 \\
\hline Very dissatisfied & $2-0$ & $5(8)$ & 2 & 3 \\
\hline
\end{tabular}

such as iontophoresis, botulinum toxin injection, and aluminum-based topical antiperspirant agents were applied to $95 \%$ of the patients; however, the results were unsatisfactory because of the inadequate or temporary benefits of these methods. The mean procedure time was 45 minute (range, 30-75 $\mathrm{min}$ ). There were no major operative complications. Conversion to thoracotomy was not required. The patients were divided into two groups according to the type of interruption (-Table 2). Cauterization of the ganglia was applied in $28(47 \%)$ patients (Group A), and clipping was applied in 32 (53\%) patients (Group B). The success rate was $93 \%$ for Group A and $100 \%$ for Group B $(p=0.35)$. Two patients underwent reoperations for early recurrences (within the first week) of $\mathrm{PH}$; both were in Group A. CH was the most common side effect, in 43 (71.6\%) patients (Group A, $71.4 \%$; Group B, $71.8 \% ; p=0.8$ ). The reflex sweating was mild in $28 \%$, moderate in $47 \%$, and severe in $26 \%$ of the patients with $\mathrm{CH}$.
The satisfaction rate was $85 \%$ in the series ( $83 \%$ for Group A and $86 \%$ for Group B [ $p=0.77]$ ). Group A scored 7.3 points on the satisfaction scale, and Group B scored 7.8 points $(p=0.3)$. Two patients (7\%) in Group A and three (9\%) patients in Group $B$ requested reversal because of severe compensatory sweating. In patients with severe $\mathrm{CH}$, removal of the clips and anticholinergic drugs were applied. The clips were removed respectively at weeks 4,7 , and 13 . The anticholinergic drugs could be used for only up to 3 weeks because of serious side effects such as urine retention, sexual dysfunction, blurred vision, and excessive drying of the mouth. Both methods were unsuccessful in controlling the side effects. Overdrying of the hands was the second most common side effect, being identified in $12(20 \%)$ patients. This side effect required continuous hydration of the hands with a lotion or cream.

Recurrence of $\mathrm{PH}$ was observed in 15 (25\%) patients; however, the amount of sweating did not require reoperation. It was well tolerated and took the form of moistened hands,

Table 2 Characteristics and comparison of the techniques

\begin{tabular}{|c|c|c|c|c|}
\hline Variables & $\begin{array}{l}\text { All patients } \\
N=60\end{array}$ & $\begin{array}{l}\text { Group A } \\
n=28\end{array}$ & $\begin{array}{l}\text { Group B } \\
n=32\end{array}$ & $p$ value \\
\hline Age, mean $\pm S D$ & $24.1 \pm 6.2$ & $24.7 \pm 7.4$ & $23.6 \pm 5$ & 0.5 \\
\hline \multicolumn{4}{|l|}{ Gender } & 0.35 \\
\hline Female & $36(60 \%)$ & 18 & 18 & \\
\hline Male & $24(40 \%)$ & 10 & 14 & \\
\hline Body mass index & 25.13 & 25.43 & 24.86 & \\
\hline \multicolumn{4}{|l|}{ Sweating region } & 0.17 \\
\hline Hand & $22(37 \%)$ & 8 & 14 & \\
\hline Hand and axilla & $38(63 \%)$ & 20 & 18 & \\
\hline Complications (pneumothorax) & $6(10 \%)$ & 3 & 3 & 0.85 \\
\hline Compensatory hyperhidrosis & 43 & 20 & 23 & 0.8 \\
\hline Mild & $12(28 \%)$ & $7(59 \%)$ & $5(41 \%)$ & \\
\hline Moderate & $20(46 \%)$ & $8(40 \%)$ & $12(60 \%)$ & \\
\hline Severe & $11(26 \%)$ & $5(45 \%)$ & $6(55 \%)$ & \\
\hline Request for reversibility & $5(8 \%)$ & 2 & 3 & 0.7 \\
\hline Satisfaction level & 7.6 & 7.2 & 7.8 & 0.3 \\
\hline Recurrence & $15(25 \%)$ & 11 & 4 & 0.01 \\
\hline
\end{tabular}

Abbreviation: SD, standard deviation. 
forearms, and armpits. In Group A, the recurrence rate was higher (19 vs. $6 \% ; p=0.01$ ). Pneumothorax was the only surgical complication, being identified in six patients (10\%). A chest tube was required in three patients. The mean followup time was $33 \pm 10.8$ months (range, 13-53 months).

\section{Discussion}

Since the first description of sympathectomy in the 1920s, surgical treatment of $\mathrm{PH}$ has evolved. Initially, the risk of surgery was thought to outweigh the potential benefits for this benign condition; therefore, surgical treatment was not as popular as it is today. Advances in video-thoracoscopic surgery have significantly facilitated and universalized thoracic sympathectomy for treatment of idiopathic $\mathrm{PH} .{ }^{8}$ Studies of the surgical treatment of PH have shown that VATS sympathectomy is very effective to stop excessive sweating when the interruption level was T2 and T3 or T4. ${ }^{9}$ However, some serious side effects of the surgery led to modification of the technique. $\mathrm{CH}$ is the most common side effect in the literature, with an incidence of 3 to $98 \%$, and is usually near $80 \%$. There is a trend toward fewer interruptions and lowerlevel blockade on the chain to increase patient satisfaction with a lower incidence of side effects and complications. ${ }^{10,11}$ For example, severe compensatory sweating was more common in T2 than in T3 and T4 sympathectomies. ${ }^{12}$ In our department, single level (R3) sympathectomy has been performed as the surgical treatment for $\mathrm{PH}$ since 2008. In our series, $\mathrm{CH}$ was the most common side effect, being identified in $71 \%$ of the patients. Horner syndrome and cardiac side effects did not appear in our series. Avoidance of higher sympathetic ganglia, such as $\mathrm{T} 1$ and $\mathrm{T} 2$, can help to prevent the occurrence of these side effects.

It is well established that success rates and patient satisfaction are very high in patients who undergo VATS sympathectomy. ${ }^{13}$ Disruption of the sympathetic ganglia by electrocautery is highly effective for relief of $\mathrm{PH}$, but it is irreversible in the event of severe compensatory sweating. Theoretically, clipping the sympathetic chain has the potential for reversibility by removing the clips. Therefore, the clipping technique has become more popular. In our clinic, electrocautery ablation was performed with high success rates. Serious side effects such as severe $\mathrm{CH}$ led us to use clipping due to the potential reversibility of the technique.

When compensatory sweating is moderate or severe, management is difficult and usually unsuccessful. In cases of intolerable compensatory sweating, topical or systemic anticholinergics can be used with variable success, but the results are usually unsatisfactory. To revert the blockade effects, removing the clips by a reoperation is feasible; therefore, clipping is more attractive not only to patients but also to surgeons. The optional time for clip removal is controversial, but may be considered to be "as soon as possible" following the appearance of intolerable $\mathrm{CH}$. However, severe $\mathrm{CH}$ can be well tolerated after surgery because of the pleasure of cessation of the PH. The patient and the surgeon may hope for spontaneous recovery of $\mathrm{CH}$ and postpone the surgery for clip removal. Lin et al reported that the clips should be removed 2 weeks after clipping, whereas Reisfeld suggested that clip removal may be applied within 6 months. ${ }^{3,14}$ In a study by Sugimura et al, clip removal resulted in a substantial decrease in $\mathrm{CH}$ in $48 \%$ of the patients, and no relationship was found between clip removal time and reversibility of the side effects. ${ }^{11}$ However, in recent studies by Loscertales et al and Candas et al, clipping the sympathetic chain resulted in irreversible changes. The sympathetic nerves were degenerated within 2 days, and no regeneration was observed in the long term, even when the clips had been removed. ${ }^{15,16}$ Sural nerve reversal was promising for intolerable $\mathrm{CH}^{17}$; however, technical difficulties in reconstruction of the nerve prevent wide implementation of the technique. Therefore, nerve grafting is difficult to accept as a treatment option. ${ }^{18}$ In our study, severe $\mathrm{CH}$ was observed in 11 (18\%) patients, 5 of whom required reversal of the sympathectomy. In three patients, the clips were removed at weeks 4,7 , and 14 after the sympathectomy. No benefit from removal of the clips was observed at the short- or long-term follow-up. Although the request for reversal of the surgery is rare, there is no effective treatment option for patients with severe $\mathrm{CH}$.

A standardized approach to evaluating the factors that affect patient satisfaction is necessary. ${ }^{19}$ Cauterization and clipping techniques are performed with similar success rates and a high satisfaction level. In a review by Kopelman and Hashmonai, neither surgical technique nor limiting or lowering the blockade level affected postoperative $\mathrm{CH}^{12}$ In a study by Li et al, limiting the extent of sympathectomy using blood flow and palmar temperature resulted in high success and satisfaction rates (100 and $92 \%$, respectively), and the incidence of mild $\mathrm{CH}$ was $12 \%$, moderate $\mathrm{CH}$ was $8 \%$, and severe $\mathrm{CH}$ was $6 \%{ }^{10}$ Although intolerable $\mathrm{CH}$ is unavoidable, it is not common and can be further reduced by careful patient preparation and the use of a standardized surgical approach. ${ }^{20}$ In our series, according to the satisfaction scale, $85 \%$ of patients were satisfied, whereas the success rate was 98\%. The satisfaction score was 7.2 for Group A and 7.8 for Group B (maximum score, 10$)(p=0.3)$. The surgical technique used did not affect the satisfaction rate. In this study, nine (15\%) patients were dissatisfied. The reason for dissatisfaction was severe $\mathrm{CH}$ in six patients, moderate $\mathrm{CH}$ in two patients, and overly dry hands in one patient. Severe $\mathrm{CH}$ occurred in 5 of 28 (18\%) patients in Group A and 6 of 32 (19\%) patients in Group B $(p=0.8)$. Both types of interruption had similar results in terms of the satisfaction rate and severity of $\mathrm{CH}$. Even if most of the patients were very satisfied with the sympathectomy, an unhappy minority (9\%) regretted the surgery, and reversibility of the side effects seems to be a remote possibility.

Recurrence of PH may depend on the reinnervation of the sympathetic chain due to insufficient blockade or interruption of the ganglia. ${ }^{5} \mathrm{PH}$ may recur early if the correct level of division is not achieved. In our series, two patients underwent reoperations in the early postoperative period because of unilateral persistent sweating. Both patients were in Group A, and a wider disruption (R2) was applied to the sympathetic ganglia. In the long-term follow-up, mild upper lip sweating 
symptoms recurred in 15 (25\%) patients; however, no patient required reoperation. Recurrences were found in 11 patients in Group A and 4 in Group B $(p=0.01)$. The cauterization group was more than likely to experience recurrence despite total disruption of the sympathetic chain. In an expert consensus document, Cerfolio et al stated that to prevent regrowth of the sympathetic chain, sufficient separation is necessary. Therefore, the ablation technique was not recommended. ${ }^{5}$ Of the 28 patients in Group A, 11 (40\%) experienced recurrence in the form of moistened hands, forearms, and armpits. In our opinion, recurrence depends not only on the technique, but also on timing. The patients were followed up for 13 to 53 months. Recurrence was observed frequently in patients operated on previously an average of 37 months after the surgery. Finally, recurrence was most common in Group A and increased with time. This type of sweating did not reduce patients' satisfaction; on the contrary, moistened hands were considered better than overly dry hands. Interestingly, $\mathrm{CH}$ continued in patients with recurrence.

Our study had some limitations. It was retrospective in design using data collected prospectively; therefore, randomization was not possible. Few patients were included in each group. Nevertheless, both cauterization and clipping were performed at a single center by the same surgical team using a standardized technique.

In conclusion, superiority of clipping to cauterization was not demonstrated. Both surgical techniques were comparable in terms of effectiveness and side effects. The recurrence rate was higher in the cauterization group, with no reduction in the satisfaction level. The reversibility of these procedures in cases of intolerable $\mathrm{CH}$ is controversial and not corroborated. Patients who undergo transection or resection of the sympathetic chain have no option of reversibility, whereas blockade with clipping gives some hope to both the surgeon and the patient. Thus, it appears that ideal candidate selection and informing patients about the serious side effects of the procedure are paramount in the surgical treatment of $\mathrm{PH}$.

\section{References}

1 Drott C, Claes G. Hyperhidrosis treated by thoracoscopic sympathicotomy. Cardiovasc Surg 1996;4(6):788-790, discussion 790791

2 Krasna MJ. The role of surgical treatment of hyperhidrosis. Mayo Clin Proc 2011;86(8):717-718

3 Lin TS, Fang HY. Transthoracic endoscopic sympathectomy in the treatment of palmar hyperhidrosis-with emphasis on perioperative management (1,360 case analyses). Surg Neurol 1999;52(5): 453-457
4 Chang YT, Li HP, Lee JY, et al. Treatment of palmar hyperhidrosis: T (4) level compared with T(3) and T(2). Ann Surg 2007;246(2): 330-336

5 Cerfolio RJ, De Campos JR, Bryant AS, et al. The Society of Thoracic Surgeons expert consensus for the surgical treatment of hyperhidrosis. Ann Thorac Surg 2011;91(5):1642-1648

6 Doolabh N, Horswell S, Williams M, et al. Thoracoscopic sympathectomy for hyperhidrosis: indications and results. Ann Thorac Surg 2004;77(2):410-414, discussion 414

7 Krasna MJ. Thoracoscopic sympathectomy: a standardized approach to therapy for hyperhidrosis. Ann Thorac Surg 2008;85 (2):S764-S767

8 Panhofer P, Zacherl J, Jakesz R, Bischof G, Neumayer C. Improved quality of life after sympathetic block for upper limb hyperhidrosis. Br J Surg 2006;93(5):582-586

9 Dewey TM, Herbert MA, Hill SL, Prince SL, Mack MJ. One-year follow-up after thoracoscopic sympathectomy for hyperhidrosis: outcomes and consequences. Ann Thorac Surg 2006;81(4):12271232, discussion 1232-1233

10 Li X, Tu YR, Lin M, Lai FC, Chen JF, Miao HW. Minimizing endoscopic thoracic sympathectomy for primary palmar hyperhidrosis: guided by palmar skin temperature and laser Doppler blood flow. Ann Thorac Surg 2009;87(2):427-431

11 Sugimura H, Spratt EH, Compeau CG, Kattail D, Shargall Y. Thoracoscopic sympathetic clipping for hyperhidrosis: long-term results and reversibility. J Thorac Cardiovasc Surg 2009;137 (6):1370-1376, discussion 1376-1377

12 Kopelman D, Hashmonai M. The correlation between the method of sympathetic ablation for palmar hyperhidrosis and the occurrence of compensatory hyperhidrosis: a review. World J Surg 2008;32(11):2343-2356

13 Vanderhelst E, De Keukeleire T, Verbanck S, Vincken W, Noppen M. Quality of life and patient satisfaction after video-assisted thoracic sympathicolysis for essential hyperhidrosis: a follow-up of 138 patients. J Laparoendosc Adv Surg Tech A 2011;21(10): 905-909

14 Reisfeld R. Sympathectomy for hyperhidrosis: should we place the clamps at T2-T3 or T3-T4? Clin Auton Res 2006;16(6):384-389

15 Loscertales J, Congregado M, Jimenez-Merchan R, et al. Sympathetic chain clipping for hyperhidrosis is not a reversible procedure. Surg Endosc 2012;26(5):1258-1263

16 Candas F, Gorur R, Haholu A, et al. The effects of clipping on thoracic sympathetic nerve in rabbits: early and late histopathological findings. Thorac Cardiovasc Surg 2012;60(4):280-284

17 Telaranta T. Secondary sympathetic chain reconstruction after endoscopic thoracic sympathicotomy. Eur J Surg Suppl 1998; (580):17-18

18 Fibla JJ, Molins L, Mier JM, Vidal G. Effectiveness of sympathetic block by clipping in the treatment of hyperhidrosis and facial blushing. Interact Cardiovasc Thorac Surg 2009;9(6):970-972

19 Lin CC, Telaranta T. Lin-Telaranta classification: the importance of different procedures for different indications in sympathetic surgery. Ann Chir Gynaecol 2001;90(3):161-166

20 Rodríguez PM, Freixinet JL, Hussein M, et al. Side effects, complications and outcome of thoracoscopic sympathectomy for palmar and axillary hyperhidrosis in 406 patients. Eur J Cardiothorac Surg 2008;34(3):514-519 